\title{
Teacher cognition in foreign language vocabulary teaching : a study of Iranian high school EFL teachers.
}

\begin{abstract}
Notwithstanding the relevance of teacher cognition inquiries, which has already become a tradition in our field, and exploration made to the many covert aspects of second language (L2) teachers' pedagogical thought processes, previous research has not fully taken vocabulary as a curricular area into account from L2 teachers' frame of reference. This inquiry sought to investigate vocabulary teaching approaches and challenges in some Iranian high schools from L2 teachers' perspectives thorough a basic qualitative research design in which a multiple qualitative data collection methods has been employed. Participants were purposefully selected and data collected through this method has been the foundation for the ensuing and interpretation. Findings indicate that although participants possessed a good deal of knowledge about English language teaching in general and vocabulary instruction in particular, approaches they employed to teach vocabulary are not in congruence with their real beliefs and do not essentially include any metacognitive and socio-affective strategies. However, major problems L2 teachers face with in vocabulary teaching are identified to be either related to the educational system or to the contextual factors.
\end{abstract}

Keyword: Teachers' knowledge; Teachers' beliefs; Teachers' cognitions. 